\title{
The Recognition of Reduced Word Forms
}

\author{
Mirjam Ernestus, Harald Baayen, and Rob Schreuder \\ Interfaculty Research Unit for Language and Speech, Max-Planck Institute for Psycholinguistics, \\ University of Nijmegen, Nijmegen, The Netherlands
}

\begin{abstract}
This article addresses the recognition of reduced word forms, which are frequent in casual speech. We describe two experiments on Dutch showing that listeners only recognize highly reduced forms well when these forms are presented in their full context and that the probability that a listener recognizes a word form in limited context is strongly correlated with the degree of reduction of the form. Moreover, we show that the effect of degree of reduction can only partly be interpreted as the effect of the intelligibility of the acoustic signal, which is negatively correlated with degree of reduction. We discuss the consequences of our findings for models of spoken word recognition and especially for the role that storage plays in these models. (๑) 2002 Elsevier Science (USA)
\end{abstract}

Key Words: spoken word recognition; reduced forms; mental lexicon; Dutch.

The type of speech that we are most often confronted with is casual speech, the everyday speech used in informal situations when no special attention is paid to expression (cf. Labov, 1972, p. 86). Nevertheless, it is only recently that some studies (e.g., Gaskell \& Marslen-Wilson, 1996, 1998; Zwitserlood \& Coenen, 2000; Cutler, 1998 , for an overview) have been devoted to the effects of casual speech phenomena on word recognition. These studies are based on speech recorded in laboratories, that is, under unnatural conditions. They provide insights into the exact effects of a number of phenomena, but fail to investigate the effects of the combination of these phenomena as they occur in natural speech. The question arises as to what real, casual speech can teach us about word recognition and about the part that storage plays in recognition.

In this article, we discuss the recognition of reduced word forms in casual Dutch. Words can appear in highly reduced forms in Dutch, as in other Germanic languages (see, e.g., Kohler, 1990; Keating, 1998). Consider the examples in (1), which are the result of multiple reduction processes.

(1) Highly reduced word forms in Dutch (Ernestus, 2000, p. 137).

\begin{tabular}{|c|c|c|c|}
\hline & $\begin{array}{l}\text { Unreduced } \\
\text { form }\end{array}$ & $\begin{array}{l}\text { Highly } \\
\text { reduced form }\end{array}$ & \\
\hline natuurlijk & /na'tyrlək & [n'tyk] & "of course", \\
\hline daarom & /'darom/ & ['dam] & "therefore", \\
\hline ongeveer & /,oyxə'ver/ & [o'ver] & "approximately" \\
\hline allemaal & /'aləmal/ & ['amal] & “all'" \\
\hline in ieder geval & /In'idər xə,val/ & ['ival] & "in any case", \\
\hline
\end{tabular}

Address correspondence and reprint requests to Mirjam Ernestus, Max-Planck Institute for Psycholinguistics, University of Nijmegen, P.O. Box 310, 6500 AH Nijmegen, The Netherlands. E-mail: Mirjam .Ernestus@mpi.nl. 
It has been shown that single deletion processes affect how quickly and accurately listeners recognize words (see Cutler, 1998, for an overview of relevant studies). If recognition accuracy is correlated with degree of reduction, highly reduced word forms may not be recognizable at all on the basis of their own acoustic signal only. Their recognition might depend to a considerable extent on their semantic/syntactic context.

We report two experiments investigating how degree of reduction and size of context affect the recognition of word forms. We observed effects for both reduction and context. We discuss the implications of our findings for psycholinguistic models of spoken word recognition.

\section{EXPERIMENT 1}

In order to investigate the effects of degree of reduction and context size on the recognition of word forms, we carried out an experiment in which participants listened to word forms and reported in written form the words that they had heard. We presented word forms with three degrees of reduction (Low, Medium, High) in their Full Context, in Limited Context together with the adjacent vowels and intervening consonants, and in an Isolation Context without any of their phonetic and syntactic/ semantic context. The three kinds of context provide different amounts of syntactic/ semantic information as well as phonetic information. Listeners have no access to syntactic and semantic context when the word forms are presented in the Isolation Context. They also do not have access to all phonetic cues when the forms are presented in the Isolation Context, since the interpretation of some of these cues depends on phonetic context. For instance, the interpretation of a vowel as tense or lax in Dutch is based on its length given the rate of speech, and rate of speech can only be determined if one more vowel is available (Nooteboom, 1979; Nooteboom \& Doodeman, 1980). Moreover, listeners are unable to accurately interpret the acoustic signal when words are presented without any context because it is only when they can identify the segments adjacent to the relevant word forms that they are able to determine whether acoustic characteristics of the initial and final segments of these forms result from coarticulation or from assimilation (cf. Gaskell \& Marslen-Wilson, 1996, 1998; Zwitserlood \& Coenen, 2000). Since listeners have access neither to semantic/syntactic context nor to phonetic context when the word forms are presented in the Isolation Context, we can determine the exact effects of semantic/syntactic context only by comparing the recognition of word forms presented in their Full Context to their recognition in both the Limited Context, in which most phonetic cues are present, and in the Isolation Context. We investigate the effects of phonetic context by comparing the recognition of word forms presented in the Isolation Context to their recognition in the Limited Context without phonetic context. Finally, the effects of Degree of Reduction are investigated by presenting the participants forms of different reduction degrees.

\section{Method}

Materials. We selected 54 stretches of speech from a corpus of spontaneous casual conversations recorded in a soundproof room (Ernestus, 2000, pp. 87-103). Each of these stretches of speech contains one target word form, and the 54 target forms are listed in the Appendix. These targets forms are the (reduced) variants of 20 different words, which we henceforth refer to as Word Types. The forms fall into the following three classes of reduction. First, there is the class of forms with Low (little or no) Reduction. The forms in this class are the least reduced forms of a Word Type in casual speech, e.g., ['moxələk] "'possible.', The second class is the class of forms with Medium Reduction. These forms are reduced, but consist of more segments than the initial, the final, and the stressed segments of their unreduced counterparts, e.g., ['moxək] mogelijk "possible." The final class consists of forms with High Reduction. These forms are reduced and consist maximally of the initial, final, and stressed segments 
of their unreduced counterparts, e.g., ['mok] mogelijk " possible.', The classifications of the word forms were based on the unanimous transcriptions of three trained phoneticians who listened to the stretches of speech containing the word forms as well as the four preceding and four following syllables. The phoneticians could replay these stretches as often as they thought was necessary for a reliable transcription. In addition to the target items, there were 55 filler items and 30 practice items, which also varied in degree of reduction. We presented all forms in three contexts. First, in the Full Context, we presented the complete sentences in which the word forms were realized, e.g., [zo snel mok nar ə:] zo snel mogelijk naar eh "'as fast as possible to uhm.' Second, in the Limited Context, we presented the forms together with the adjacent vowels and intervening consonants, e.g., [عl mok na] el mogelijk naa "ast possible to." Finally, we presented the forms in the Isolation Context, cut away from their context, e.g., [mok] mogelijk "possible."

In summary, there are 20 Word Types (mogelijk, eigenlijk, natuurlijk, etc.), which are represented by 54 word forms with different degrees of reduction (Low, Medium, and High). These forms are presented in three kinds of context (Full, Limited, and Isolation).

Procedure. Participants listened to stretches of speech over headphones (Sony NMR-55), with each stretch of speech being presented only once. The participants identified the words contained in these stretches by writing them down according to their normal spelling. For instance, if they perceived the word form [cik] and identified it as a form of eigenlijk with the canonical form [cixələk], they wrote down eigenlijk. The experiment was self-paced. Participants were presented with a new stretch of speech only after they had indicated that they were ready by pushing a button. All items were presented in all contexts.

Participants. Sixty participants, 20 for each context, were paid to participate in the experiment. All participants were native speakers of Dutch, and most of them were undergraduates at Nijmegen University. The participants were assigned to one of six groups, each group hearing the stretches of speech in a different random order.

\section{Results and Discussion}

The numbers of participants who did not correctly recognize the presented word forms for the Full Context, the Limited Context, and the Isolation Context are listed in the Appendix. Figure 1 shows the average percentages of misidentifications for the three context classes broken up by degree of reduction. Figure 1 shows that all forms are recognized fairly accurately when presented in their Full Context. In the Limited Context and in the Isolation Context, forms with Low or Medium Reduction are also

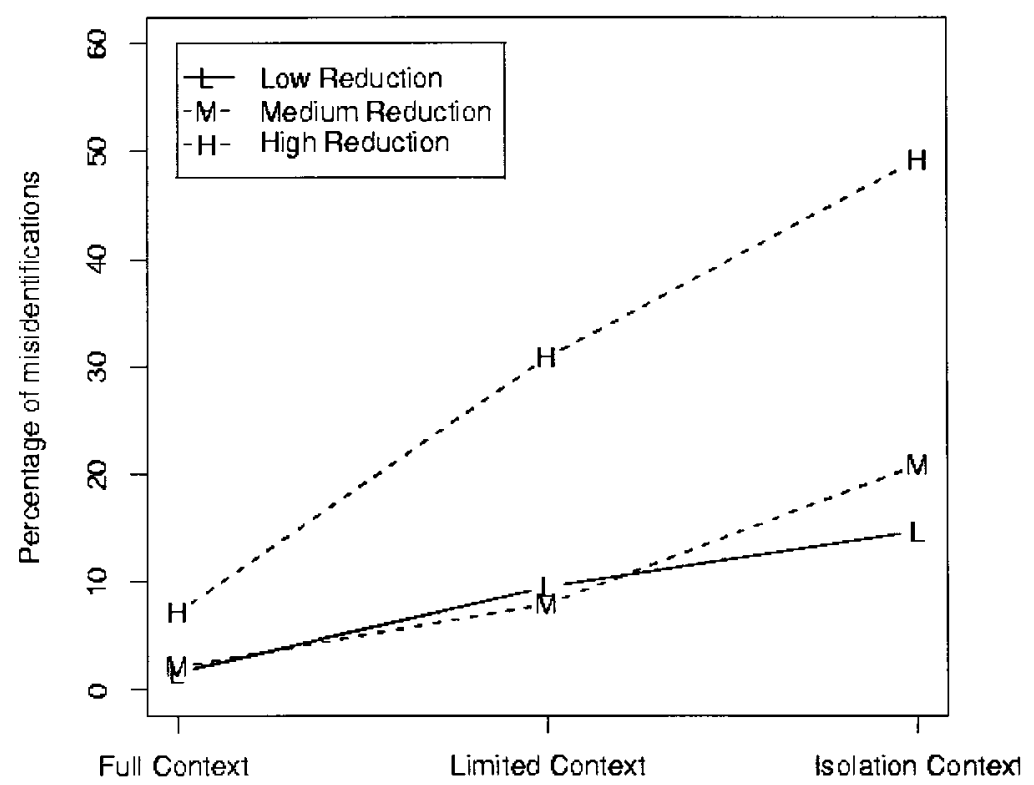

FIG. 1. The average percentages of misidentifications for the forms with Low, Medium, and High Reduction in three types of context. 
recognized reasonably accurately. By contrast, forms with High Reduction are recognized less well. A linear regression analysis of the logit of the numbers of correct and incorrect identifications on the factors Context, Degree of Reduction, and Word Type reveals significant main effects of Context $[F(2,137)=26.03, p<.0001$ : the larger the context the higher the amount of correct identifications], Degree of Reduction $[F(2$, $137)=16.33, p<.0001$ : the lower the degree of reduction the higher the amount of correct identifications], and of Word Type $[F(19,137)=2.44, p=.0016$ : some word types are recognized better than others]. The interaction of Context and Degree of Reduction is significant as well $[F(4,137)=2.84, p=.0265]$. A similar analysis of the numbers of correct and incorrect identifications in only the Full and Limited Contexts provides roughly the same results: Context $[F(1,85)=2.08, p=.0008]$, Degree of Reduction $[F(2,85)=8.57, p=.0004]$, and Word Type $[F(19,85)=2.08, p=$ .00122] present significant main effects, while the interaction between Context and Degree of Reduction $[F(2,85)=2.80, p=.0665]$ just misses significance. An analysis of the numbers of correct and incorrect identifications in the Limited and Isolation Contexts, on the contrary, reveals no trace of interaction between Degree of Reduction and Context $[F(2,85)=0.70, p=.50]$. The main effects of Context $[F(1,85)=$ $11.74, p=.0009]$, Degree of Reduction $[F(2,85)=14.77, p<.0001]$, and Word Type $[F(19,85)=2.33, p=.0044]$ are again significant. In summary, Context, Degree of Reduction, and Word Type are important factors. The overall interaction between Context and Degree of Reduction is due to the Full and Limited Contexts.

It is surprising that even Highly Reduced forms are recognized very accurately in their Full Context, given that they are recognized rather poorly in the Limited Context, as indicated by the interaction of Context and Degree of Reduction that originated precisely from the Full and Limited Contexts. These high recognition scores may be due to two factors. First, the Full Context may provide sufficient constraining semantic and syntactic information to allow participants to infer the word forms from minimal phonetic cues. Second, the Full Context may provide more phonetic cues than the other contexts. This second possibility is at odds with the increase of misidentifications when we go from the Full Context to the Limited Context, since we constructed the Limited Context in such a way that most phonetic cues available in the Full Context are still present. Moreover, if the difference between the Full and Limited Contexts for the Highly Reduced forms only resulted from a difference in available phonetic cues, this difference in cues should also have affected the recognition of forms with Medium and Low Reduction to a large extent, contrary to fact. Apparently, the data only support the hypothesis that syntactic/semantic context facilitates the recognition of Highly Reduced forms.

Note that the semantic and syntactic context may well facilitate recognition since some of the word types have high probabilities to occur given their full context. For instance, the probability that the word type mogelijk "possible" follows the phrase zo snel "as fast as" is high, and the probability that volgens "according to" precedes mij "me" is high as well.

The analysis of the Limited and Isolation Contexts presented above revealed Context, Degree of Reduction, and Word Type as main effects, with a nonsignificant interaction of Context and Degree of Reduction. In other words, removal of phonetic context leads to more misidentifications, independently of Degree of Reduction. In addition, Highly Reduced word forms elicit more misidentifications than word forms with Medium or Low Reduction, independently of Context. The absence of an interaction between Context and Degree of Reduction for the differences between the Limited and Isolation Contexts is in line with the hypothesis that only the characteristics of the acoustic signal can play a role in these contexts and no semantic/syntactic information is available. 
The overall pattern of results suggests that the forms with a High Degree of Reduction benefit from semantic and syntactic context, as evidenced by the interaction between Context and Degree of Reduction. The more problematic the identification, the more semantic and syntactic context facilitate processing. Independently of Degree of Reduction, all forms benefit when there is more phonetic context available.

The effect of Degree of Reduction might be interpreted as resulting from other factors. First, it might be interpreted as an effect of frequency of occurrence of the forms with Low, Medium, and High Reduction. Higher frequency words are recognized faster (Rubenstein et al., 1970; Forster \& Chambers, 1973). It might be the case that word forms with a High Degree of Reduction occur less frequently than forms with less reduction and that this is the reason that the Highly Reduced forms are recognized less accurately. However, frequency of occurrence probably cannot account for the differences in the recognition accuracy between word forms with Low and Medium Reduction. It is our impression, based on our work on corpora of spontaneous spoken Dutch, that the word types incorporated in our experiment occur more frequently with Medium Reduction than with Low Reduction in everyday speech. We even had difficulties finding unreduced forms of some word types, such as helemaal, inderdaad, and allemaal, in the corpus of casual Dutch from which we took our materials for the experiment. If this impression is correct, it remains unclear why the forms with Low Reduction are reported equally accurately as the (higher frequency) forms with Medium Reduction. On the basis of the limited information that is currently available on the frequencies of spoken word forms, it seems unlikely that frequency of occurrence is the key to the understanding of our pattern of results.

Second, the effect of Degree of Reduction might be interpreted as an effect of the intelligibility of the acoustic signal. Reduced forms typically occur in that type of speech in which all kinds of phonetic contrasts disappear, making it difficult to distinguish $[\mathrm{t}] \mathrm{s}$ from $[\mathrm{d}] \mathrm{s}$, [t]s from $[\mathrm{s}] \mathrm{s}$, and so on, and introducing uncertainty whether vowels and sonorants such as the [r] or [1] are present. Degree of Reduction might have been found to affect the percentages of misidentifications, due to a negative correlation between degree of reduction and the intelligibility of the acoustic signal.

In what follows, we investigate whether the effect of Degree of Reduction is entirely the effect of the intelligibility of the acoustic signal or whether degree of reduction still plays a part of its own. We take as our point of departure our identification scores obtained in Experiment 1. We restrict ourselves to the scores obtained for the forms presented in the Isolation Context, since these forms were recognized the least accurately. In order to investigate the effect of the intelligibility of the acoustic signal, we determined listeners' interpretation of the signals representing these forms in the Isolation Context, that is, the phonemic representations established by the listeners for these signals. These phonemic representations are not necessarily identical to the transcriptions provided by the three phoneticians for use in Experiment 1, since these transcriptions were based on stretches of speech forming the full context of the word forms instead of on stretches of speech just containing the word forms at issue. The phoneticians had access to more phonetic cues than the listeners hearing the word forms in the Isolation Context did, and their phonemic representations are probably slightly different. We determined the phonemic representations on the basis of the phonetic transcriptions provided by the listeners in Experiment 2.

\section{EXPERIMENT 2}

\section{Method}

Materials. The materials consist of the same 54 target word forms as used in Experiment 1, plus seven practice items, which were also taken from Experiment 1. 
Procedure. Participants transcribed phonetically the word forms that we presented to them in the Isolation Context. They used a simple phonetic system which is very close to the Dutch spelling system. For instance, if they perceived [cik], which is a reduced form of eigenlijk, with the canonical form [عikələk], they wrote down eik. The participants heard the items only once, like the listeners in Experiment 1 did. The experiment was again self-paced. Participants were presented with a new word form only after they had indicated that they were ready by pushing a button.

Participants. Ten native speakers of Dutch and students at Nijmegen University were paid to participate in the experiment. They were assigned to one of six groups, each group hearing the stretches of speech in a different order.

\section{Results and Discussion}

The transcriptions provided by the 10 participants were translated into the International Phonetic Alphabet. These translations can be found in the Appendix.

In order to determine the effect of the intelligibility of the acoustic signal, we defined the "Intelligibility," or, better, "Unintelligibility," of a word form as the average relative difference between each transcription provided by the participants for this word form and the closest "Possible Phonetic Form" of the corresponding Word Type. We define Possible Phonetic Forms as forms that are related to the unreduced form by general reduction processes, such as deletion of liquids, deletion of [t] in consonant clusters, vowel reduction, and deletion of unstressed vowels (cf. Ernestus, 2000, pp. 107-144). We quantify the Unintelligibility of a word form by means of the average number of segments that are different in the two forms divided by the number of segments in the relevant Possible Phonetic Form. We do not count differences in vowel quality and in single features, since these types of differences appear not to contribute much to the unintelligibility of the signal. Experiments have shown that listeners readily alter vowels to turn a nonword into a real word (van Ooijen, 1996) and words may be activated especially if they differ from the input by just a single specific feature (e.g., Bölte \& Coenen, 2000; Zwitserlood \& Coenen, 2000).

The more segments there are in a phonetic form, the more differences there can be between the phonemic representation as established by a listener and the closest Possible Phonetic Form of the corresponding word type. This implies that if we defined the unintelligibility of the signal as just the number of differences, there would be a positive correlation between the length of a phonetic form and its unintelligibility. This is contrary to fact: It is certainly not more difficult to recognize long forms than short ones. We therefore normalize the number of differences with respect to the number of segments in the relevant Possible Phonetic Form.

To give an example, we assigned an Unintelligibility score of 0.10 to the word form which was transcribed as [as], a phonetic form of als "if", by the three phoneticians for use in Experiment 1. This word was transcribed in Experiment 2 as [als], the canonical form, by one participant; as [as] by two participants; as [os] by four participants; and, finally, as [osp], [ols], and [pos] by the remaining three participants (see the Appendix). The forms [as], [als], [os], and [ols] do not contribute to the Unintelligibility of the signal. The form [als] is identical to the corresponding canonical form. The form [as] differs from the canonical form only in that the frequent deletion process of coda [1] has applied. The forms [os] and [ols] differ from the preceding two forms only in the quality of their vowels. In all, there are therefore eight transcriptions which do not contribute to the Unintelligibility of this signal. The two forms [əsp] and [pos], on the other hand, do contribute to the Unintelligibility, since they deviate substantially from the canonical form of als. They are closest to the Possible Phonetic Form [as], but they have an extra irreducible segment. Their Unintelligibility is 1 (number of differences)/2 (number of segments in [as]). In sum, 
the Unintelligibility of this phonetic form is $[(8 * 0)+0.5+0.5] / 10=0.10$. The Unintelligibility scores for all forms, which were calculated in this way, can be found in the Appendix.

As predicted, there is a correlation between Unintelligibility and percentage of misidentifications: If the Unintelligibility of a word form increases, the percentage of misidentifications increases as well $[r=.67, t(52)=4.899, p=.0001]$. Apparently, the effect of degree of reduction attested in Experiment 1 can at least partly be ascribed to the unintelligibility of the acoustic signal.

In order to determine whether degree of reduction proper plays a role in word recognition in addition to the unintelligibility of the signal, we investigated the effect of the combination of unintelligibility and degree of reduction proper. We defined new scores, which we refer to as Deviation scores, as the number of deletions, substitutions, and additions required to transform a given word form into its corresponding full canonical form divided by the length of this canonical form. For instance, the Deviation score of the word form [os], given the canonical form [als], equals 2/3. As we have 10, often different, phonetic transcriptions for a given experimental word form, the Deviation score for an experimental word form is obtained by averaging over the normalized distances, as was done for the Unintelligibility scores. The resulting Deviation scores can be found in the Appendix.

When counting the number of deletions, additions, and substitutions, we take every difference into account, including differences in vowel quality and differences between consonants differing in single features, because it is not at all clear which differences should be counted and how they might be weighted. For instance, it is not clear whether the absence of [1] is worse than the difference between [o] and [a]. In this way, we obtain a measure, albeit crude, of distance to the canonical form that allows us to state numerically that both [as] and [ols] differ from the canonical form [als].

Figure 2 shows the correlation between the percentages of misidentification and

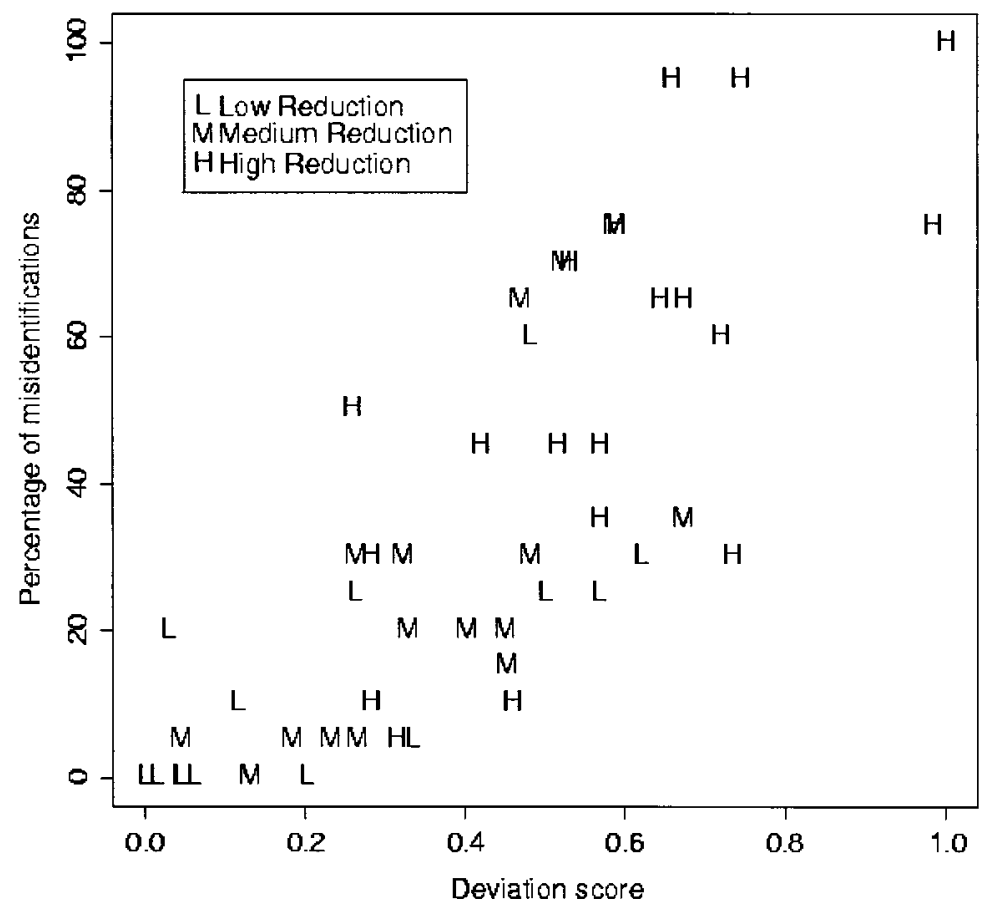

FIG. 2. The percentage of misidentifications as a function of Deviation score. 
the Deviation scores of the word forms presented in the Isolation Context. The data points in the figure are indicated with the letters $L, M$, and $H$, and refer to the reduction classification used in Experiment 1.

The percentage of misidentifications emerges as a linear function of the Deviation scores $[r=.81, t(52)=10.26, p<.0001]$. A logit analysis in which both the Unintelligibility and Deviation scores are included as predictors of the numbers of correctly and incorrectly identified word forms reveals [note that they are strongly correlated to each other, $r=.71, t(52)=7.33, p<.0001]$ the Deviation score to be the only statistically significant predictor $[F(1,51)=60.87, p<.0001$; Unintelligibility: $F<1]$. We conclude that the Deviation score, which measures both Unintelligibility and Degree of Reduction, is a better predictor of the percentage of misidentifications than a measure of Unintelligibility by itself.

\section{GENERAL DISCUSSION}

This study reports two experiments investigating the recognition of word forms in casual speech. Experiment 1 shows that phonetic context as well as syntactic/ semantic context facilitate the recognition of word forms. Highly reduced word forms are well recognizable, but only when they are presented in their full context. Full context favors recognition because it provides listeners not only with all phonetic cues but also with semantic and syntactic information. This finding challenges pure bottom-up models of word recognition such as Shortlist (Norris, 1994), at least with respect to the processing of highly reduced forms. The observation that the Limited Context allows better identification than the Isolation Context underlines the relevance of phonetic context for establishing phonemic representations. This is an issue that has as yet received no systematic attention in the psycholinguistic literature.

In addition, Experiment 1 shows that if forms are presented in the Isolation Context or in the Limited Context, recognition is correlated with the degree of reduction of the forms. It is more difficult to recognize highly reduced forms than less reduced forms. We ascertained, on the basis of the transcriptions obtained in Experiment 2, that the effect of degree of reduction is in part an effect of unintelligibility. Listeners have difficulties recognizing highly reduced forms because it is difficult to establish phonemic representations on the basis of the acoustic signals expressing these forms. Nevertheless, the attested correlation between degree of reduction and recognition accuracy appears to be due also to degree of reduction proper. If the phonetic distance between a reduced form and the corresponding canonical form increases, recognition of the form detoriates.

An important question concerning the recognition of reduced word forms is the role of potential storage of reduced forms in the mental lexicon. Two extreme hypotheses can be postulated: The mental lexicon might contain all Possible Phonetic Forms of all word types, allowing direct form-based lexical access, or, alternatively, the mental lexicon might contain only one representation for every word type, reflecting its unreduced form, in which case reduced forms are recognized following processes of reconstruction.

Our finding that degree of reduction proper affects recognition accuracy suggests that there is no simple storage of all Possible Phonetic Forms. If all Possible Phonetic Forms would have their own access representations and if these representations would all be equally well accessible, one would expect that all Possible Phonetic Forms would be equally easy or difficult to recognize, contrary to fact. Clearly, models assuming extensive storage require additional ancillary assumptions, e.g., that forms differ in their resting activation levels or that certain phonetic forms can be accessed 
only under certain conditions. In this respect, the Shortlist model is also challenged. Shortlist can easily handle reduction phenomena as long as reduced forms are stored in the mental lexicon, but it cannot explain the effect of degree of reduction proper on recognition accuracy.

Models which assume that the mental lexicon contains access representations only for the canonical forms, for instance, the model developed by Gaskell and MarslenWilson (1996, 1998), can incorporate the effect of degree of reduction proper on recognition accuracy without difficulties. The larger the difference between a reduced form and the canonical form, the more reconstruction is necessary, and the more often recognition will be problematic. Further research is required, however, to elucidate the precise nature of the mapping process linking highly reduced forms such as [cik] (eigenlijk "in fact") to their canonical form ([cixələk]).

\section{APPENDIX}

The following table lists for every word form in the experiment its phonetic transcription according to the three trained phoneticians; its word type; the canonical form of this word type; Degree of reduction (High, Medium, or Low); the number of participants (of 20) who did not recognize the form presented in Full Context, Limited Context, and Isolation Context in Experiment 1; the IPA translations of the phonetic transcriptions obtained in Experiment 2; and the Unintelligibility and Deviation scores.

[als] als, [als], L, “if,' (0, 14, 5), (4 [os], 2 [as], [als], [ols], [osp], [pəs]), (0.10, $0.57)$.

[as] als, [als], H, “if,' (0, 3, 7), (4 [as], [als], [asp], [pas], [varsx], [vars], [vas]), (0.25, 0.57).

[altcit] altijd, [altcit], L, “always," (0, 0, 0), (7 [altcit], [altət], [daltcit], [talteit]), (0.04, 0.06).

[altət] altijd, [alteit], M, “always,', (0, 1, 6), ([aldIt], [alsət], [alt], [altd], [altcit], [altət], [atcit], [bəpal], [van], [velalt]), (0.20, 0.48).

[amal] allemaal, [aləmal], L, “all,' (1, 1, 1), (3 [aləmal], 2 [almal], [almal], [amal], [oməp], [oləmal], [olma]), (0.03, 0.33).

[ama] allemaal, [aləmal], M, “all,’' (0, 18, 5), (3 [عlma], 2 [jama], [amar], [alm], [almal], [hemal], [jama]), $(0.13,0.58)$.

[as] anders, [als], H, “other,' (0, 0, 9), (4 [ans], 2 [ands], 2 [andəs], [andrs], [lann]), (0.10, 0.42).

[bəpaldə] bepaalde, [bəpaldə], L, “certain,’’ (0, 0, 0), (10 [bəpaldə]), (0.00, $0.00)$.

[pəpaldə] bepaalde, [bəpaldə], L, “certain,', (0, 0, 0), (8 [bəpaldə], [bəpaldə], [bəpalt]), (0.00, 0.01).

[palə] bepaalde, [bəpaldə], H, “certain,', $(0,1,2)$, (4 [paldə], [bpaldə], [pal], [paul], [paulə], [pauə], [plaulə]), $(0.22,0.46)$.

[darom] daarom, [darom], L, “therefore,' (0, 0, 0), (8 [darэm], [daэm], [darom]), (0.00, 0.04).

[darəm] daarom, [darəm], M, “therefore," (0, 0, 4), (2 [arəm], 2 [darəm], 2 [varom], 2 [varm], [darəm], [vərns]), $(0.19,0.32)$.

[dam] daarom, [darom], H, “therefore,', $(0,2,6),(4$ [darm], 3 [dam], [dan], [darəm], [darəm]), $(0.00,0.28)$. 
[عixələk] eigenlijk, [عixələk], L, “actually," $(0,0,0),(8$ [عixələk], [عixəlık], [عixənlək]), $(0.00,0.00)$.

[عixək] eigenlijk, [cixələk], M, “actually,” (0, 0, 13), (6 [عixə], [cixl], [عixn], [عixək], [عixənlə]), (0.32, 0.47).

[eixk] eigenlijk, [cixələk], M, “actually," $(0,0,3),(5$ [cixə], 2 [cixlək], [arx], [cixək], [cixəl]), (0.23, 0.45).

[cix] eigenlijk, [cixələk], H, "actually," (0, 18, 10), (3 [kleix], ], 2 [tveix], [cixl], [klarx], [klei], [of cix], [weix]), (1.03, 0.98).

[xə] gaan, [xan], H, “to go," (0, 20, 20), ([fə], [ft], [pr], [ps], [təv], [təuy], [y], [vet], [xd], [zy]), $(0.42,1.00)$.

[xəvon] gewoon, [xəvon], L, "normally,', $(3,3,5),(2$ [xuon], [kan], [klaə],

[kmn], [xan], [xay], [xəvan], [xəvon], [xuən]), $(0.03,0.50)$.

[xuon] gewoon, [xəvon], H, “normally," $(0,4,2),(6$ [xvon], [tun], [tvan], [təvon], [xəvon]), (0.08, 0.28).

[xon] gewoon, [xəvon], H, "normally," $(0,1,6),(2$ [an], [anv], [tran], [trav], [tron], [xon], [xun], [xuon], -), (0.48, 0.73).

[heləmal] helemaal, [heləmal], L, "completely," $(0,0,0)$, (6 [heləmal], 3 [eləmal], [helamal]), (0.05, 0.04).

[helmal] helemaal, [heləmal], M, “completely," $(0,0,0)$, (4 [helmal], 4 [heləmal], [elma], [elmal]), (0.04, 0.13).

[helmal] helemaal, [heləmal], M, "completely," $(0,0,7),(3$ [jama], 2 [hemal], [Imy], [Imər], [Irmə], [jamr], [jamə]), (0.12, 0.67).

[heməl] helemaal, [heləmal], H, “completely," (0, 0, 9), (2 [hemal], [eləma], [hemal], [hləmal], [Irma], [jama], [jmal], [velma], [vilə]), (0.07, 0.51).

[huvə] hoeveel, [huvel], L, "how much," $(0,0,6)$, ([dhuvə], [də huvə],

[də uvər], [huvə], [huvəl], [hvevy], [lofa], [lovər], [uvə], [əhuve]), $(0.18,0.62)$.

[huvəl] hoeveel, [huvel], L, "how much," (0, 7, 12), ([duval], [hufal], [huvl],

[høvəl], [nufəl], [tuv], [ufo], [ufə], [uvə], [yfo]), (0.13, 0.48).

[Inərdat] inderdaad, [Indərdat], L, “indeed," $(0,0,0),(7$ [Indərdat], 2 [Indədat], [Inərdat]), $(0.00,0.04)$.

[Idat] inderdaad, [Indərdat], H, “indeed," (2, 7, 1), (3 [Indat], 2 [Indərdat], [Inat], [Indrdat], [Inərdat], [rat], [Ydat]), (0.03, 0.31).

[In ixəval] in ieder geval, [In idər xəval], L, “in any case," (1, 13, 5), (2 [Inidərxəval], 2 [Inixəval], [idəval], [Inidərval], [Inirxəval], [mamixəvauvən], [nixəvalə], -), (0.06, 0.26).

[Inival] in ieder geval, [In idər xəval], M, “in any case," $(0,0,1),(2$ [Inirxəval], 2 [Inival], [Inidərxval], [Inidərxəval], [Inidəval], [Inirxval], [Inixval], [Inixəva]), $(0.00,0.26)$.

[idəval] in ieder geval, [In idər xəval], M, “in any case," $(2,1,14)$, ([edərval], [edəva], [edəvan], [edəvat], [idərxəval], [ixəval], [Inidərval], [Inival], [reləvant], [telyfo]), $(0.15,0.52)$.

[ival] in ieder geval, [In idər xəval], $\mathrm{H}$, "in any case," $(8,18,12)$, (2 [ival], 2 [yvon], [hirvo], [Inidəxval], [nivan], [yval], [yvo], [yvol]), (0.25, 0.72).

[moxələk] mogelijk, [moxələk], L, “possible,” (0, 0, 0), (9 [moxələk], [moxələ]), $(0.02,0.01)$.

[moxək] mogelijk, [moxələk], M, "possible," (0, 0, 4), (3 [moxə], 2 [mərxə], [mərə], [moxəlk], [moxələk], [məxə], [moxən]), (0.21, 0.40). 
[mok] mogelijk, [moxələk], H, “possible,' (0, 18, 13), (3 [moj], 2 [mo], 2 [morx] [moxə], [məxə], [mərxə]), (0.44, 0.64).

[natylək] natuurlijk, [natyrlək], L, “naturally,', (0, 0, 4), (7 [natyrlək], 2 [natylək], -), (0.00, 0.03).

[nətylək] natuurlijk, [natyrlək], M, “naturally,', (0, 0, 4), (2 [natylək], [atyrlək], [ivılık], [natylk], [ntylık], [ntylək], [nətyrlək], [vilık], [ənœylə]), (0.11, 0.33).

[nətyk] natuurlijk, [natyrlək], H, “naturally,', (3, 1, 13), (2-, 2 [natyr], [atyr], [etjə], [enty], [InzIx], [InzIxt], [ntjə]), (0.53, 0.67).

[tyk] natuurlijk, [natyrlək], H, "naturally," (0, 5, 9), (3 [tyk], 2 [tyk], 2 [tøk], [døk], [tylk], [tyrk]), (0.00, 0.57).

[oxəver] ongeveer, [эฤxəver], L, “approximately,', (1, 0, 0), (9 [эџxәver], [ōxəve]), $(0.00,0.01)$.

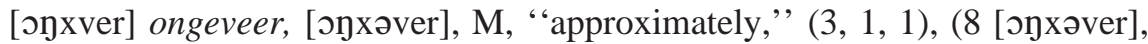
[onver], [oxəver]), (0.00, 0.04).

[ofer] ongeveer, [o๊xəver], H, “'approximately,', (10, 21, 19), (4 [ofjə], [bovel], [ovel], [ofucl], [pofjə], [ufel], [ufjə]), (0.05, 0.74).

[эp әxevəment] op een gegeven moment, [əp ən xəxevən moment], L, “at a certain moment,"' $(0,0,0),(2$ [opənxevənment], [opbəxevənmoment], [วpxevəmen], [эpxevəment], [วpxevənmoment], [วpxəxevəmoment], [วpənxevənmoment], [วpənxəxevənmoment], [วpəxəxevəmoment]), (0.01, $0.20)$.

[эрәxement] op een gegeven moment, [эp ən xəxevən moment], M, “at a certain moment,' (0, 0, 0), ([əpbəxevəməmt], [əpnxəxevəmoment], [əpxəxevəment],

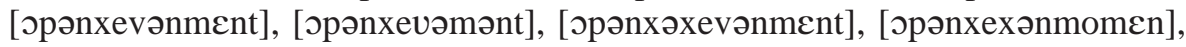
[эpəxevmomen], [วpəxevəmen], [эpəxəxefmoment]), $(0.03,0.23)$.

[əpəxemt] op een gegeven moment, [op ən xəxevən moment], M, “'at a certain moment,' (1, 5, 2), ([эpxe], [opxefmom], [эpxemu], [эpxevə],

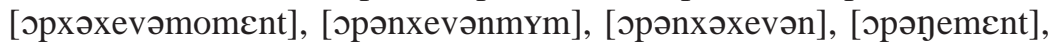
[эpəxefm], [opəxevəmen]), (0.12, 0.45).

[วpxef] op een gegeven moment, [эp ən xəxevən moment], $\mathrm{H}$, “at a certain moment,' (2, 3, 6), (3 [opxev], [эpxe], [эpxi], [эpənxe], [эpənxəxevə], [วpəxevə], [วрәxәxev], -), (0.18, 0.59).

[fวxənt] volgend, [volxənt], L, “next,', $(0,0,2)$, (4 [volxənt], 3 [volxəns], [volxns], [volxən], [volxəs]), (0.01, 0.11).

[folnt] volgend, [volxənt], H, “next,', (0, 0, 10), (4 [vont], [volxəns], [volxənt], [volxəs], [vəlxət], [vələnt], [vวxənt]), $(0.10,0.26)$.

[foz] volgens, [volxəns], H, “according to,' (1, 1, 14), (5 [vol], [bvobd], [bəvorbelt], [pfolb], [volx], [vor]), (0.49, 0.66).

[fo] volgens, [volxəns], H, “'according to,' (1, 0, 19), (6 [vəs], 2 [vols], [vəsp], [vวxวs]), (0.03, 0.53).

[vasxcinlək] waarschijnlijk, [varsxcinlək], L, “probably,” $(0,0,0)$,

(8 [varsxcinlək], [varsxcinlk], [vərsxcinlək]), (0.00, 0.01).

[vasxcink] waarschijnlijk, [varsxeinlək], M, “probably,'” $(0,0,1)$, (3 [varsxcin], 2 [varsxcinl], 2 [varsxeinlk], [varsxcinlə], [varsxcinlək], [varsxeink]), (0.08, 0.18).

[varsxein] waarschijnlijk, [varsxcinlək], M, 'probably,' $(1,2,6)$, (6 [varsxein], 2 [varsxeinl], [varsxcilək] [varsxcinlək]), (0.18, 0.26). 


\section{REFERENCES}

Bölte, J., \& Coenen, E. (2000). Domato primes paprika: Mismatching pseudowords activate semantic and phonological representations. Presented at the SWAP workshop, Nijmegen, 1999.

Cutler, A. (1998). The recognition of spoken words with variable representations. In Proceedings of the ESCA workshop on sound patterns of spontaneous speech (pp. 83-92).

Ernestus, M. (2000). Voice assimilation and segment reduction in casual Dutch: A corpus-based study of the phonology-phonetics interface. Utrecht: LOT.

Forster, K. I., \& Chambers, S. M. (1973). Lexical access and naming time. Journal of Verbal Learning and Verbal Behaviour, 12, 627-635.

Gaskell, M. G., \& Marslen-Wilson, D. (1996). Phonological variation and inference in lexical access. Journal of Experimental Psychology: Human Perception and Performance, 22, 144-158.

Gaskell, M. G., \& Marslen-Wilson, D. (1998). Mechanisms of phonological inference in speech production. Journal of Experimental Psychology: Human Perception and Performance, 24, 380-396.

Keating, P. (1998). Word-level phonetic variation in large speech corpora. In A. Alexiadou, N. Fuhrhop, U. Kleinhenz, \& P. Law (Eds.), ZAS papers in linguistics (vol. 11, pp. 35-50). Berlin: Zentrum für Allgemeine Sprachwissenschaft, Typologie und Universalienforschung.

Kohler, K. J. (1990). Segmental reduction in connected speech in German: Phonological facts and phonetic explanations. In W. J. Hardcastle \& A. Marchal (Eds.), Speech production and speech modelling (pp. 69-92). Dordrecht: Kluwer.

Labov, W. (1972). Sociolinguistic patterns. Philadelphia: Univ. of Pennsylvania Press.

Nooteboom, S. G. (1979). Perceptual adjustments to speech rate: A case of backward perceptual normalization. In H. V. Deighton-van Witsen (Ed.), Anniversaries in phonetics: Studia gratulatoria dedicated to Hendrik Mol (pp. 225-269). Amsterdam: Institute of Phonetic Sciences.

Nooteboom, S. G., \& Doodeman, G. J. N. (1980). Production and perception of vowel length in spoken sentences. Journal of the Acoustical Society of America, 67, 276-287.

Norris, D. G. (1994). Shortlist: A connectionist model of continuous speech recognition. Cognition, 52, 189-234.

van Ooijen, B. (1996). Vowel mutability and lexical selection in English: Evidence from a word reconstruction task. Memory \& Cognition, 24, 573-583.

Rubenstein, H., Garfield, L., \& Millikan, J. (1970). Homographic entries in the internal lexicon. Journal of Verbal Learning and Verbal Behavior, 9, 487-499.

Zwitserlood, P., \& Coenen, E. (2000). Consequences of assimilation for word recognition and lexical representation. Presented at the SWAP workshop, Nijmegen, 1999. 